\title{
Olanzapine-Induced Cirrhosis and Hepatocellular Carcinoma by Hepatotoxicity in An Elder Chinese Woman: Case Report and Review of The Literature
}

\author{
Youwen Tan*, Li Sun and Xinbei Zhou \\ Department of Hepatosis, The Third Hospital of Zhenjiang Zhenjiang, China \\ *Corresponding author: Youwen Tan, Department of Hepatosis, The Third Hospital of Zhenjiang Zhenjiang, China
}

\begin{tabular}{|c|c|}
\hline ARTICLE INFO & ABSTRACT \\
\hline Received: 幽 July 01, 2019 & \multirow{7}{*}{$\begin{array}{l}\text { Olanzapine is an atypical antipsychotic that is used currently in the treatment of } \\
\text { schizophrenia and bipolar illness, we present a case of a 75-year-old Chinese woman } \\
\text { with schizophrenia for } 30 \text { years who used a long-term use of olanzapine developed } \\
\text { to cirrhosis and hepatocellular carcinoma. We used RUCAM (Method for causality } \\
\text { assessment of adverse drug reactions) to score } 7 \text { points by hepatotoxicity of olanzapine. } \\
\text { Pathologist thought the patient probly caused by non-alcoholic steatohepatitis (NASH) for } \\
\text { establishing the diagnosis of steatohepatitis are based on the presence of abnormalities } \\
\text { associated with significant hepatocellular injury in the setting of steatosis. We expect to } \\
\text { see patients receiving olanzapine should be educated about its potential adverse effects } \\
\text { and complications. }\end{array}$} \\
\hline Published: 幽 July 09, 2019 & \\
\hline Citation: Youwen Tan, Li Sun, Xinbei & \\
\hline Zhou. Olanzapine-Induced Cirrhosis & \\
\hline and Hepatocellular Carcinoma by & \\
\hline Hepatotoxicity in An Elder Chinese & \\
\hline $\begin{array}{l}\text { Woman: Case Report and Review of } \\
\text { The Literature. Biomed J Sci \& Tech Res }\end{array}$ & \\
\hline
\end{tabular}
19(3)-2019. BJSTR. MS.ID.003308.

Abbreviations: TACE: Transcatheter Arterial Chemoembolization, CT: Computed Tomography

Keywords: Olanzapine; Hepatotoxicity; Non-Alcoholic Steatohepatitis; Cirrhosis; Hepatocellular Carcinoma

\section{Introduction}

Hepatitis and cholestatic jaundice are common complications of the use of conventional antipsychotics, particularly chlorpromazine. Olanzapine is an atypical antipsychotic that is used currently in the treatment of schizophrenia and bipolar illness [1], olanzapine is not infrequently associated with serum aminotransferase elevations during therapy and there have been rare instances of clinically apparent acute liver injury linked to its use. Liver test abnormalities have been reported to occur in $10 \%$ to $50 \%$ of patients on long term therapy with olanzapine [2]. These abnormalities are usually mild, asymptomatic and transient, and can reverse even with continuation of medication [3]. We present a rare case. A elder Chinese woman with cirrhosis and hepatocellular carcinoma maybe induced by a longtime olanzapine- hepatotoxicity.

\section{Ethics Statement}

The study was approved by the Medical Ethics Committee of the Third Hospital of Zhenjiang Affiliated Jiangsu University, and written informed consent was obtained from the patient. The study was conducted in accordance with the Declaration of Helsinki.

\section{Case Report}

A 75- year- old Chinese woman was brought to our outpatient department by her son who noted that she was complaining upper abdominal discomfort for one month. Physical examination found her sclera yellow dye and liver enlargement. then, biochemistry tests and a computed tomography (CT) scan of the upper abdomina were made. She had no family or personal history of liver disease or no history of alcohol, diabetes or substance abuse. However, the patient has a long-term use of olanzapine( $5 \mathrm{mg} 15 \mathrm{mg}, 1 \sim 3$ times per a day), intermittent taking pentafluoride history(10 mg 20 mg, 1 times per a week) because of schizophrenia and bipolar illness for more than 30 years, liver function is not often detected, occasionally slightly elevated alanine aminotransferase, Her body mass index was $22.9 \mathrm{~kg} / \mathrm{m}^{2}$. Her liver biochemistry tests showed an elevated 
alkaline phosphatase $641 \mathrm{U} / \mathrm{L}$,(reference range, 50-120 U/L),glutamine transpeptidase $725 \mathrm{U} / \mathrm{L}$ (10-40 U/L),alanine aminotransferase $126 \mathrm{U} / \mathrm{L}(10-40 \mathrm{U} / \mathrm{L})$, and total bilirubin $34,6 \mu \mathrm{mol} / \mathrm{L} \mathrm{(5-21}$ $\mu \mathrm{mol} / \mathrm{L})$, glucose $4.53 \mathrm{mmol} / \mathrm{L}(3.9-6.1 \mathrm{mmol} / \mathrm{L})$, triglycerides (TG) $0.86 \mathrm{mmol} / \mathrm{L}(0.4-1.8 \mathrm{mmol} / \mathrm{L})$, low density lipoproteins ( $\mathrm{LDL}$ ) 2.25

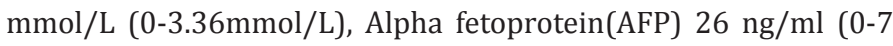
$\mathrm{ng} / \mathrm{ml}$ ). white blood cell (WBC) count, $3.7 \times 10^{9} / \mathrm{L}$, hemoglobin, 8.6 $\mathrm{g} / \mathrm{dL}$, hematocrit, $27.9 \%$ and platelet count 76000 per microliter of blood. The patient negative antibodies for nuclear antigens, smooth muscle actin, liver- kidney microsomes, soluble liver antigen/liver pancreas antigen, antimitochrondrial antibodies, and protoplasmic antineutrophil cytoplasmic antibody. Moreover, serum immunoglobulin elevation were normal and also negative serum markers of A-E virus hepatitis (Figure 1).

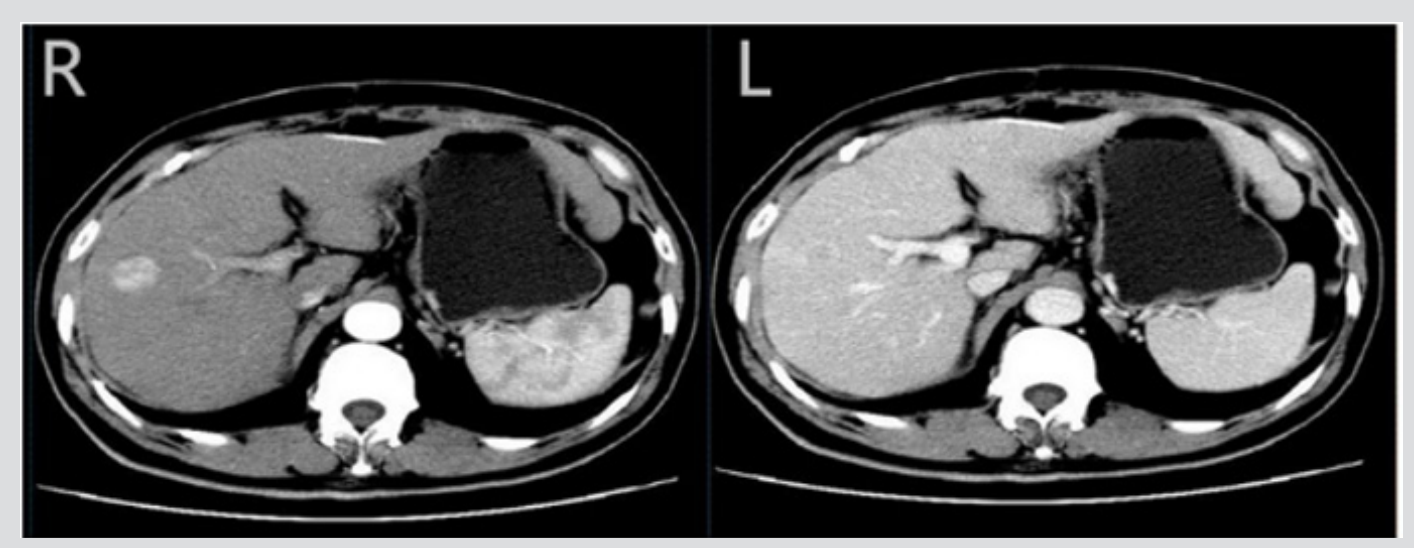

Figure 1: Computed tomography (CT) scan of the liver Computed tomography (CT) scan of the liver showed a $2 \mathrm{~cm}$ tumour in the right lobe with arterial phase hyperenhancement $(R)$ and venous phase washout $(\mathrm{L})$

A Computed tomography (CT) scan of the liver showed $2 \mathrm{~cm}$ tumors in the right lobe with arterial phase hyperenhancement and venous phase washout and background liver appeared cirrhotic. This diagnosis was confirmed by pathology, cirrhosis
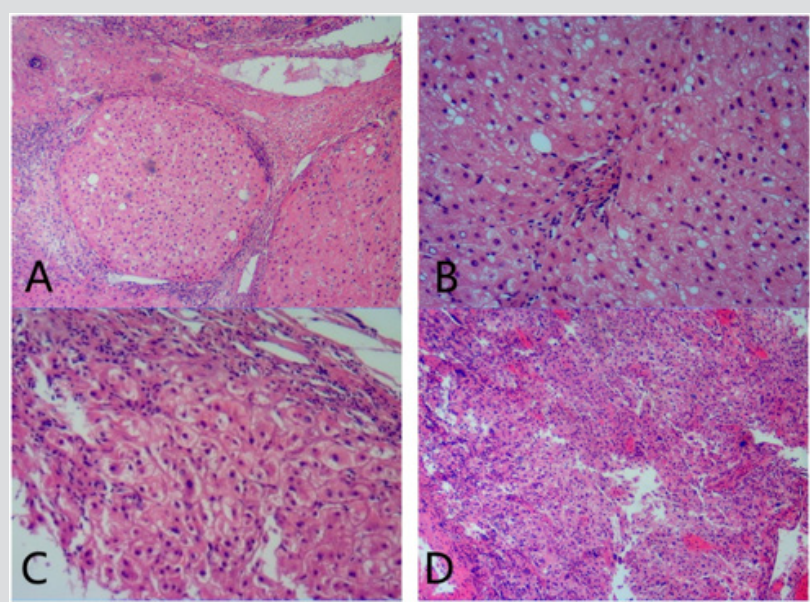

Figure 2: Pathology characters

A. Cirrhosis. Fibrous strands surround nodules composed of hepatocytes.

B. steatosis and lobular inflammation

C. hepatocytes ballooning and lobular inflammation

D. Hepatocellular carcinoma.

\section{Discussion}

Our patient fulfils the criteria for drug-induced hepatotoxicity: the absence of serological evidence of viral hepatitis, absence of chronic liver disease, absence of drug and alcohol misuse, and a temporal relation to the antipsychotic medication therapy. We used RUCAM [4] (Method for causality assessment of adverse drug and hepatocellular carcinoma, caused possibly by nonalcoholic steatohepatitis. The woman was managed with surgical method and transcatheter arterial chemoembolization (TACE) at our institution (Figure 2).

reactions) to score, the final score of 7 points (TIME TO ONSET OF THE REACTION: Suggestive, 2 points; RISK FACTOR(S) FOR DRUG REACTION: Presence, age $\geqq 55,1$ point; NON DRUG-REIATED CAUSES: Ruled out,2 points; PREVIOUS INFORMATION ON THE DRUG: Reaction labelled in the product's characteristics, 2 points;). The patient belongs to Probable : 6 8 points. The question of which of the two drugs (pentafluoride or olanzapine) caused the adverse drug reaction is more difficult to resolve because no liver biochemistry tests were performed while he was on pentafluoride therapy. However, we did not find pentafluoride hepatotoxicity from Liver Tox. Liver test abnormalities have been reported to occur in $10 \%$ to $50 \%$ of patients on long term therapy with olanzapine [5]. These abnormalities are usually mild, asymptomatic and transient, and can reverse even with continuation of medication. In addition, instances of more marked elevations in serum aminotransferase levels and clinically apparent hepatitis with jaundice have been reported in patients taking olanzapine. The pattern of serum enzyme elevations has ranged from hepatocellular to mixed and even cholestatic. Allergic manifestations (rash, fever, eosinophilia) and autoimmune markers are uncommon. The time to onset of liver injury with olanzapine therapy has varied widely, from a few weeks to a year after starting [6]. In all cases, the injury has resolved rapidly with drug discontinuation.

Cases with a long latency and accompanied by significant weight gain may represent nonalcoholic fatty liver disease, rather than 
olanzapine hepatotoxicity $[7,8]$. Olanzapine-associated cirrhosis is rare [9] (0.02\%, $n=3 / 19861$, from Liver Tox). Pathologist thought the patient cirrhosis and hepatocellular carcinoma probly caused by NASH for establishing the diagnosis of steatohepatitis are based on the presence of abnormalities associated with significant hepatocellular injury in the setting of steatosis. The close association between injury and steatosis led to the hypothesis that steatosis predisposes to injury. Although many early reviews of NASH provided tables of drugs that have been associated with steatosis or steatohepatitis [10-12], it remains unclear for most drugs if there is a causative link or if the association is coincidental because of the relatively high prevalence of NASH [13]. Olanzapineinduced weight gain +/- lifestyle and other metabolic risks causes fatty liver and steatohepatitis in this patient, although we noticed that glucose, triglyceride, total/HDL/LDL-cholesterol levels of this patient were all normal. Hepatocellular carcinoma is a recognized complication of cirrhosis in NASH patients [14]. This has recently been reviewed. In the series of 42 patients by Powell et al. [15]. HCC was reported in one. Shimada et al. [16]. reported that from 82 cases of biopsy-proven NASH, 13 were cirrhotic and six of these had HCC (7.3\% of total cohort; $47 \%$ of cirrhotics). Soga et al. [17]. reported a non-obese inbred mouse model with spontaneous fatty liver that develops steatohepatitis; with time many of the animals develop hepatocellular adenomas and hepatocellular carcinomas. The investigators $[14,18]$ reviewed other reported animal models with the propensity for HCC development, and concluded that steatosis alone is not sufficient for tumour genesis, but inflammation may be a necessary component. It is increasingly recognized that HCC may develop in the non-cirrhotic NAFLD liver $[14,19,20]$. The CATIE (Clinical Antipsychotic Trials of Intervention Effectiveness) study found that olanzapine is the best tolerated of antipsychotics, having the longest 'time-to-discontinuation' period. We expect to see a growing population of psychiatric patients receiving olanzapine. Patients should be educated about its potential adverse effects and complications.

\section{Conclusion}

Olanzapine is not infrequently associated with serum aminotransferase elevations during therapy. We present a rare case, an elder Chinese woman with cirrhosis and hepatocellular carcinoma maybe induced by a longtime olanzapine- hepatotoxicity. We used RUCAM to score 7 points. Pathologist thought the patient cirrhosis and hepatocellular carcinoma probly caused by NASH based on the presence of abnormalities associated with significant hepatocellular injury in the setting of steatosis.

\section{References}

1. Yoshimura Y, Takeda T, Kishi Y, Harada T, Nomura A, et al. (2017) Optimal Dosing of Risperidone and Olanzapine in the Maintenance Treatment for Patients with Schizophrenia and Related Psychotic Disorders: A Retrospective Multicenter Study. J Clin Psychopharmacol 37(3): 296301.
2. Yoodee J, U Permsuwan, M Nimworapan (2017) Efficacy and safety of olanzapine for the prevention of chemotherapy-induced nausea and vomiting: A systematic review and meta-analysis. Crit Rev Oncol Hematol 112: 113-125.

3. Lass J, A Mannik, JS Bell (2008) Pharmacotherapy of first episode psychosis in Estonia: comparison with national and international treatment guidelines. J Clin Pharm Ther 33(2): 165-173.

4. Danan G, C Benichou (1993) Causality assessment of adverse reactions to drugs--I. A novel method based on the conclusions of international consensus meetings: application to drug-induced liver injuries. J Clin Epidemiol 46(11): 1323-1330.

5. Mintzer J, SD Targum (2003) Psychosis in elderly patients: classification and pharmacotherapy. J Geriatr Psychiatry Neurol 16(4): 199-206.

6. Selim K, N Kaplowitz (2013) Hepatotoxicity of psychotropic drugs. Hepatology 29(5): 1347-1351.

7. Schulz C, RJ Haight (2013) Safety of olanzapine use in adolescents. Expert Opin Drug Saf 12(5): 777-782.

8. Schottle D, O Kuhnigk, D Naber (2013) Drug safety evaluation of olanzapine pamoate. Expert Opin Drug Saf 12(6): 897-903.

9. Cristancho MA, M E Thase (2014) Drug safety evaluation of olanzapine/ fluoxetine combination. Expert Opin Drug Saf 13(8): 1133-1141.

10. Choti MA (2009) Chemotherapy-associated hepatotoxicity: do we need to be concerned? Ann Surg Oncol 16(9): 2391-2394.

11.Zorzi D, Laurent A, Pawlik TM, Lauwers GY, Vauthey JN, et al. (2007) Chemotherapy-associated hepatotoxicity and surgery for colorectal liver metastases. Br J Surg 94(3): 274-286.

12. Aloia TA, B N Fahy (2010) Chemotherapy-associated hepatotoxicity: how concerned should we be? Expert Rev Anticancer Ther 10(4): 521-527.

13. Chun YS, Laurent A, Maru D, Vauthey JN (2009) Management of chemotherapy-associated hepatotoxicity in colorectal liver metastases. Lancet Oncol 10(3): 278-286.

14. Seko Y. Sumida Y, Tanaka S, Mori K, Taketani H, et al. (2016) Development of hepatocellular carcinoma in Japanese patients with biopsy-proven non-alcoholic fatty liver disease: Association between PNPLA3 genotype and hepatocarcinogenesis/fibrosis progression. Hepatol Res 47(11): 1083-1092.

15. Powell EE, Cooksley WG, Hanson R, Searle J, Halliday JW, Powell LW, et al. (1990) The natural history of nonalcoholic steatohepatitis: a follow-up study of forty-two patients for up to 21 years. Hepatology 11(1): 74-80.

16. Shimada M, Hashimoto E, Taniai M, Hasegawa K, Okuda H, et al. (2002) Hepatocellular carcinoma in patients with non-alcoholic steatohepatitis. J Hepatol 37(1): 154-160.

17. Soga M, Kishimoto Y, Kawamura Y, Inagaki S, Makino S, et al. (2003) Spontaneous development of hepatocellular carcinomas in the FLS mice with hereditary fatty liver. Cancer Lett 196(1): 43-48.

18. Wong CR, MH Nguyen, JK Lim (2016) Hepatocellular carcinoma in patients with non-alcoholic fatty liver disease. World J Gastroenterol 22(37): 8294-8303.

19. Mohamad B, Shah V, Onyshchenko M, Elshamy M1, Aucejo F, et al. (2016) Characterization of hepatocellular carcinoma (HCC) in non-alcoholic fatty liver disease (NAFLD) patients without cirrhosis. Hepatol Int 10(4): 632-639.

20. Yatsuji S, E Hashimoto (2006) [Natural history of Japanese patients with non-alcoholic fatty liver disease (NAFLD), especially non-alcoholic steatohepatitis (NASH) patients with hepatocellular carcinoma (HCC)]. Nihon Rinsho 64(6): 1173-1179. 


\section{ISSN: 2574-1241}

DOI: 10.26717/BJSTR.2019.19.003308

Youwen Tan. Biomed J Sci \& Tech Res

(c) (i) This work is licensed under Creative

Submission Link: https://biomedres.us/submit-manuscript.php

\begin{tabular}{ll} 
BIOMEDICAL & \multicolumn{1}{c}{ Assets of Publishing with us } \\
RESEARCHES & - Global archiving of articles \\
- Immediate, unrestricted online access \\
- Rttps://biomedres.us/
\end{tabular}

